\title{
Analisis Keamanan Jaringan Komputer Pada Sekolah Menengah Atas Negeri 04 Bandung
}

\author{
MochamadAkbar ${ }^{1}$,Taufik Agung Pramana², Marcellino I ${ }^{3}$, \\ Abdurahman Fauzi ${ }^{4}$ \\ Fakultas Teknik Informatika, Universitas ARS \\ Antapani, Jl. TerusanSekolah No.1-2, Cicaheum, Kec. Kiaracondong, Kota Bandung, Jawa Barat 40282 \\ Email:mochbay98@gmail.com ${ }^{1)}$,taufikagungpramana0@gmail.com², \\ marcellino.ilham00@gmail.com,abdurahman.auz@ars.ac.id
}

\begin{abstract}
ABSTRAK - Perkembangan jaringan komputer sangatlah pesat. Akses jaringan komputer terutama internet adalah kebutuhan yang tidak dapat dihindari. internet tidak hanya digunakan oleh individu, tetapi oleh instansi, organisasi, perguruan tinggi, sekolah ataupun lembaga pemerintah atau non pemerintah.kebutuhan terhadap akses jaringan komputer kini sangat tinggi, maka dibutuhkan keamanan jaringan yang memadai. Keamanan jaringan komputer adalah langkah untuk mencegah dan mengidentifikasi penggunaan yang tidak sah pada jaringan komputer. fungsimya adalah untuk mengantisipasi ancaman baik fisik maupun logik yang dapat menganggu aktifitas atau data yang ada dalam sistem pada jaringan komputer. penelitian ini merupakan penelitian kualitatif deskriptif dengan teknik pengumpulan dan penyusunan data dengan teknik triangulasi. Berdasarkan hasil penelitian, ruangan kepala sekolah dan staff tata usaha di SMAN 4 bandung telah memiliki jaringan komputer. proteksi keamanan jaringan komputer yang trdapat dalam ruangan tersebut menggunakan antivirus. Selain itu terdapat mikrotik yang digunakan untuk memblok dan juga membatasi beberapa situs yang diatur dan dikendalikan sesuai pihak sekolah.
\end{abstract}

Kata Kunci : Jaringan Komputer, Internet, Mikrotik

\section{Pendahuluan}

Informasi pada saat ini sudah menjadi sebuah kebutuhan yang sangat penting. Kemampuan untuk mengakses dan menyediakan informasi secara cepat dan akurat sangat penting bagi sebuah organisasi, baik yang berupa organisasi komersial, perguruan tinggi, lembaga pemerintahan, maupun individual[1]. Dengan perkembangan teknologi komputer dan telekomunikasi yang sangat pesat, maka diperlu adanya pertimbangan akan bahaya penyalahgunaannnya baik itu dalam layanan jaringan lokal ataupun dalam aplikasi yang berbasis internet[2].

Perkembangan Jaringan Komputer sangatlah pesat, akses terhadap internet sangat dibutuhkan oleh semua kalangan sekarang ini. Internent tidak hanya di akses untuk mencari informasi bagi orang - orang yang membutuhkannya, tetapi juga di akses oleh hacker atau cracker[3][13]. Dengan tujuan tertentu mereka melakukan penyusupan yang bisa merugikan para pemilik server dan jaringan komputer. Mereka menggunakan berbagai macam serangan jaringan komputer dengan tools yang dibuat secara mandiri ataupun yang telah ada[4]. Kecanggihan serangan dan tools pada jaringan komputer berbanding terbalik dengan pengetahuan tentang penyusupan pada jaringan komputer[5].

Keamanan jaringan komputer adalah proses untuk mencegah dan mengidentifikasi penggunaan yang tidak sah dari jaringan komputer[6]. Tujuan dari Keamanan jaringan komputer adalah untuk mengantisipasi resiko pada jaringan komputer berupa bentuk ancaman fisik maupun logik baik langsung ataupun tidak langsung mengganggu aktivitas yang sedang berlangsung dalam jaringan komputer. selain itu, untuk menjaga data pada sistem komputer agar aman dari berbagai ancaman[7].

Sekolah Menengah Atas No 4 Bandung telah mempunyai sistem jaringan komputer yang terhubung diruang kepala sekolah dan ruang staff Tata Usaha. Namun sistem jaringan komputer tesebut belum memiliki proteksi keamanan yang dapat melindungi pengguna dari ancaman fisik dan logik. Rancangan keamanan jaringan komputer yang akan dibangun di Sekolah Menengah Atas SMA Negeri 4 Bandung, dimana pada ruangan kepala sekolah dan ruangan tata usaha dapat diproteksi oleh sistem jaringan komputer. Menurut penelitian yang telah dilakukan tentang Pengembangan Sistem Pengaman Jaringan Komputer Berdasarkan Analisis Forensik Jaringan menyatakan bahwa hasil pengujian dan analisis system pengaman jaringan computer dapat dirancang menggunakan bukti forensik jaringan komputer[8][14]. Dan penyerang tidak akan mampu melakukan serangan pada waktu yang akan datang dengan menggunakan metode yang sama[9].

\section{Metode Penelitian}

Penelitian ini dilakukan di Sekolah Menengah Atas SMA Negeri 4 Bandung, dengan jenis penelitian kulitatif 
deskriptif. Subjek penelitian dalam penelitian ini adalah kepala sekolah dan staff tata usaha di Sekolah Menengah Atas SMA Negeri 4 Bandung. jenis data yang digunakan dalam penelitian ini adalah data kualitatif. Sedangkan sumber data yang digunakan adalah data primer yang berasal dari guru dan staff tata usaha dari seolah tersebut, dan data sekunder yang diperoleh dari observasi langsung kepada pihak yang terkait.

Teknik pengumpulan data yang digunakan adalah dengan cara observasi yang dilakukan kepada guru dan staff tata usaha di Sekolah Menengah Atas SMA Negeri 4 Bandung. teknik analisis yang di gunakan dalam penelitian ini adalah analisis deskriptif[10]. Pengumpulan dan penyusunan data melalui observasi dan wawancara ini dilakukan dengan menggunakan teknik triangulasi. Triangulasi adalah proses memastikan sesuatu dari berbagai sudut pandang[11]. Dalam penelitian ini, triangulasi digunakan untuk mendapatkan keakuratan data menggunakan berbagai cara, prosedur, dan metode agar data yang diperoleh dapat dipercaya kebenarannya. Beberapa macam triangulasi yang digunakan dalam penelitian ini adalah: data triangulation dan situational triangulation[12].

\section{Hasil dan pembahasan}

SMA Negeri 4 Bandung adalah sekolah menengah atas yang memiliki beberapa ruangan seperti ruang kepala sekolah, ruang wakil kepala sekolah, ruang tata usaha, ruang guru, ruang kelas, dan laboratorium komputer. Hasil wawancara di SMA Negeri 4 Bandung menyatakan bahwa jaringan komputer penting untuk di implementasikan di sekolah, karena jaringan komputer dapat mengintegerasikan seluruh komputer yang terdapat di sekolah. Subyek wawancara juga menyatakan bahwa dengan adanya jaringan komputer dapat mempermudah pekerjaan yang dilakukan karena data sudah teintegerasi dengan baik. Dengan adanya jaringan komputer, pengecekkan secara realtime data dapat dilakukan mudah oleh kepala sekolah tanpa harus bertemu langsung dengan para guru dan staff.

Hasil wawancara menyatakan bahwa ruang kepala sekolah, ruang wakil kepala sekolah, dan ruang tata usaha sudah terhubung menggunakan jaringan komputer. Sehingga ruang kepala sekolah, ruang wakil kepala sekolah, dan ruang tata usaha dapat dengan mudah menyebakan informasi dan data. Jaringan komputer yang digunakan oleh ruang kepala sekolah, ruang wakil kepala sekolah, dan ruang tata usaha merupakan jaringan nirkabel. Sehingga kepala sekolah, wakil kepala sekolah, dan staff TU dapat menggunakan komputer/laptop pribadi. Adapun tugas dari kepala sekolah, wakil kepala sekolah, dan tata usaha adalah sebagai berikut:

1. Kepala sekolah

a) Menetapkan prosedur kegiatan sekolah

b) Memimpin rapat guru

c) Mengkoordinasikan dan menjalankan pertanggungjawaban kurikulum

d) Menyusun perencanaan program kegiatan

e) Melakukan pengewasan proses belajar mengajar

f) Menyelenggarakan suvervisi

2. Wakil Kepala Sekolah

a) Membuat perencanaan kurikulum

b) Membuat laporan pertanggungjawaban kompetensi dasar kepada kepala sekolah

c) Mengkoordinasikan dan menjalankan kurikulum

d) Membantu kepala sekolah dalam kegiatan penyusunan perencanaan

e) Pengembangan keunggulan

f) Identifikasi dan pengumpulan data

3. Tata Usaha

a) Penyusunan program kerja tata usaha

b) Mengurus administrasi guru, tenaga kerja, dan siswa

c) Penyusunan dan penyajian data statistic sekolah

d) Penyususnan laporan pelaksaan kehiatan pengurusan tata usaha secara berkala

e) Penyusunan administrasi perlengkapan

Berdasarkan hasil observasi yang dilakukan di SMA Negeri 4 Bandung. Skema jaringan yang saling terhubung yaitu ruangan Kepala Sekolah, ruangan Wakil Kepala Sekolah, dan ruangan Tata Usaha. Dalam skema tersebut menggunakan topologi Star yang berpusat pada Laboratorium Komputer. Berikut skema diagram jaringannya: 


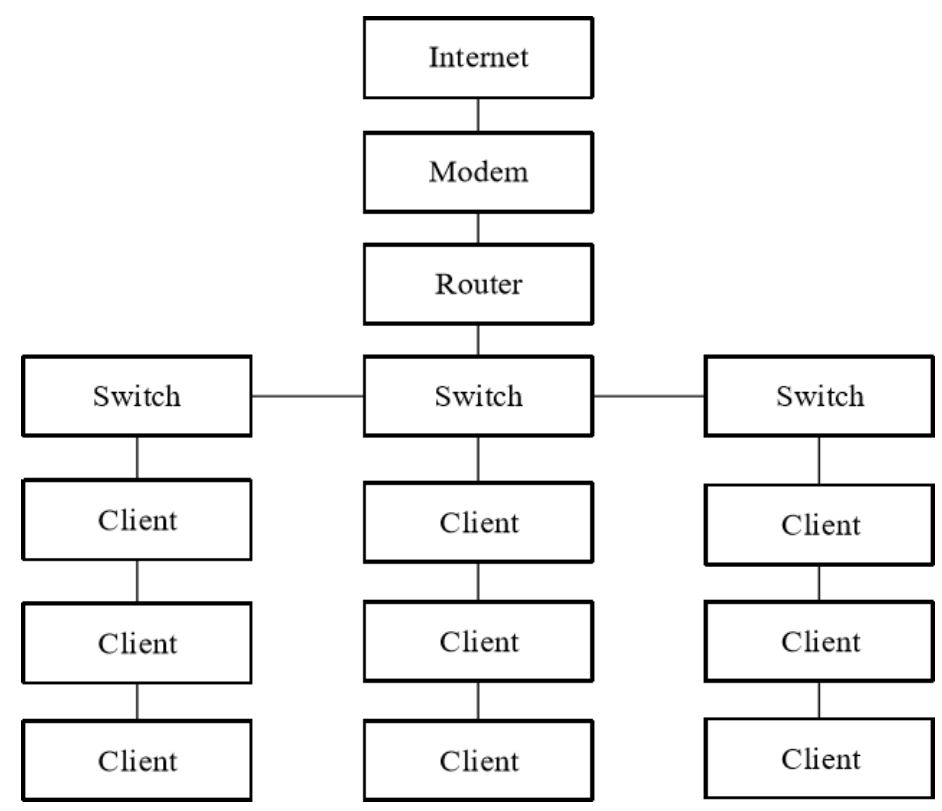

Gambar 1. Skema Diagram Jaringan

Berikut keterangan dari skema jaringan di SMAN 04 Bandung:

1. Internet: meruparakan jaringan inti dalam skema ini yang dapat menghubungkan lebih dari 2 komputer. SMK Al-Madani Pontianak berlanggan dengan IndieHome untuk dapat berkomunikasi dengan jarak yang jauh.

2. Modem: merupakan suatu alat yang digunakan untuk menghubungkan komputer melalui line kabel dari penyedia jasa telekomunikasi lainnya.

3. Router/Server: merupakan pusat pengendali yang berfungsi sebagai manajemen sistem jaringan di SMAN 04 Bandung.

4. Switch: merupakan penghubung komputer-komputer khususnya di SMAN 04 Bandung.

5. Client: merupakan komputer pengguna, dalam hal ini adalah komputer Kepala Sekolah, Wakil Kepala Sekolah, dan Staff Tata Usaha.

Skema jaringan komputer di SMAN 04 Bandung memiliki alamat-alamat yang digunakan untuk saling berkomunikasi. Alamat-alamat tersebut dikenal dengan nama IP Address.

Tabel 1. IP Address

\begin{tabular}{|c|c|c|c|c|c|}
\hline No & User & IP Address & Subnetmask & Gateaway & Ruangan \\
\hline 1 & Router & 192.168 .11 .1 & 255.255 .255 .0 & 192.168 .11 .0 & Laboratorium \\
\hline 2 & PC1 & 192.168 .11 .2 & 255.255 .255 .0 & 192.168 .11 .0 & \multirow{3}{*}{ Kepala Sekolah } \\
\hline 3 & PC2 & 192.168 .11 .3 & 255.255 .255 .0 & 192.168 .11 .0 & \\
\hline 4 & PC3 & 192.168 .11 .4 & 255.255 .255 .0 & 192.168 .11 .0 & \\
\hline 5 & PC4 & 192.168 .11 .5 & 255.255 .255 .0 & 192.168 .11 .0 & \multirow{4}{*}{$\begin{array}{l}\text { Wakil Kepala } \\
\text { Sekolah }\end{array}$} \\
\hline 6 & PC 5 & 192.168 .11 .6 & 255.255 .255 .0 & 192.168 .11 .0 & \\
\hline 7 & PC 6 & 192.168 .11 .7 & 255.255 .255 .0 & 192.168 .11 .0 & \\
\hline 8 & PC 7 & 192.168 .11 .8 & 255.255 .255 .0 & 192.168 .11 .0 & \\
\hline 9 & PC 8 & 192.168 .11 .9 & 255.255 .255 .0 & 192.168 .11 .0 & \multirow[t]{2}{*}{ Tata Usaha } \\
\hline 10 & PC 9 & 192.168 .11 .10 & 255.255 .255 .0 & 192.168 .11 .0 & \\
\hline
\end{tabular}

Berdasarkan skema tersebut, proteksi keamanan jaringan selain menggunakan antivirus juga menggunakan firewall filtering dengan menggunakan mikrotik. Berikut tampilan awal mikrotik. 


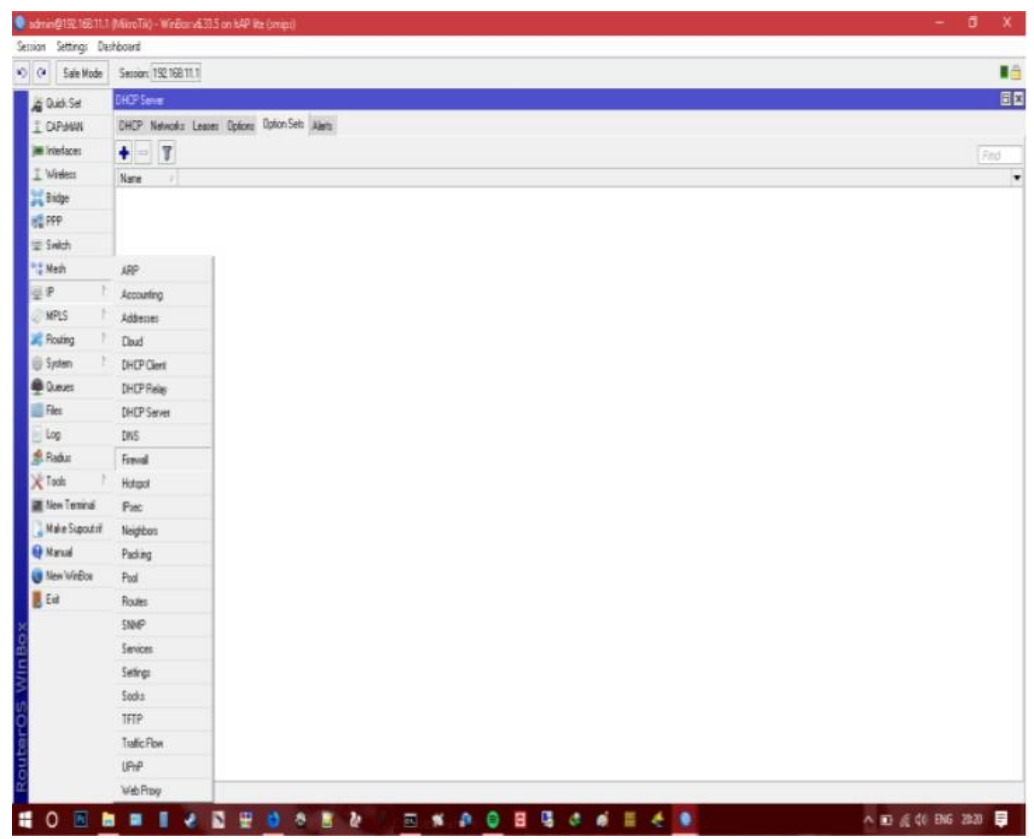

Gambar 2. Mikrotik

Aplikasi mikrotik memiliki pengaturan dalam proteksi jaringan komputer. Salah satu pengaturan yang digunakan dalam mengamankan jaringan di ruang Kepala sekolah, Wakil Kepala Sekolah, dan Tata Usaha yaitu menggunakan firewall.

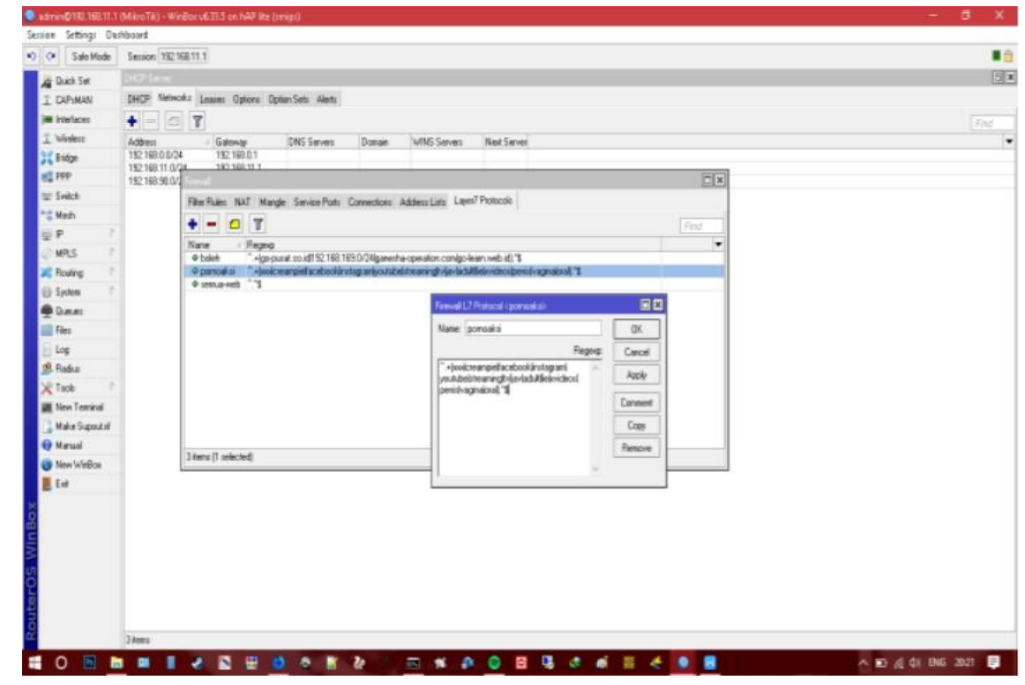

Gambar 3. Pengaturan Firewall

Pengaturan firewall dapat di masukkan rule (aturan) dalam mengamankan jaringan komputer. Dengan menggunakan tanda "+" pada rule firewall yang berisikan tentang keyword yang akan di blok pada sistem keamanan jaringan komputer. Contohnya seperti pada gambar 4.3 “^.+(xxx|facebook|instagram|youtube $\mid)$. *\$|”. Arti dari keyword tersebut adalah saat client mengakses situs dari facebook, instagram, atau youtube maka akses tersebut tidak akan diijinkan oleh server. 


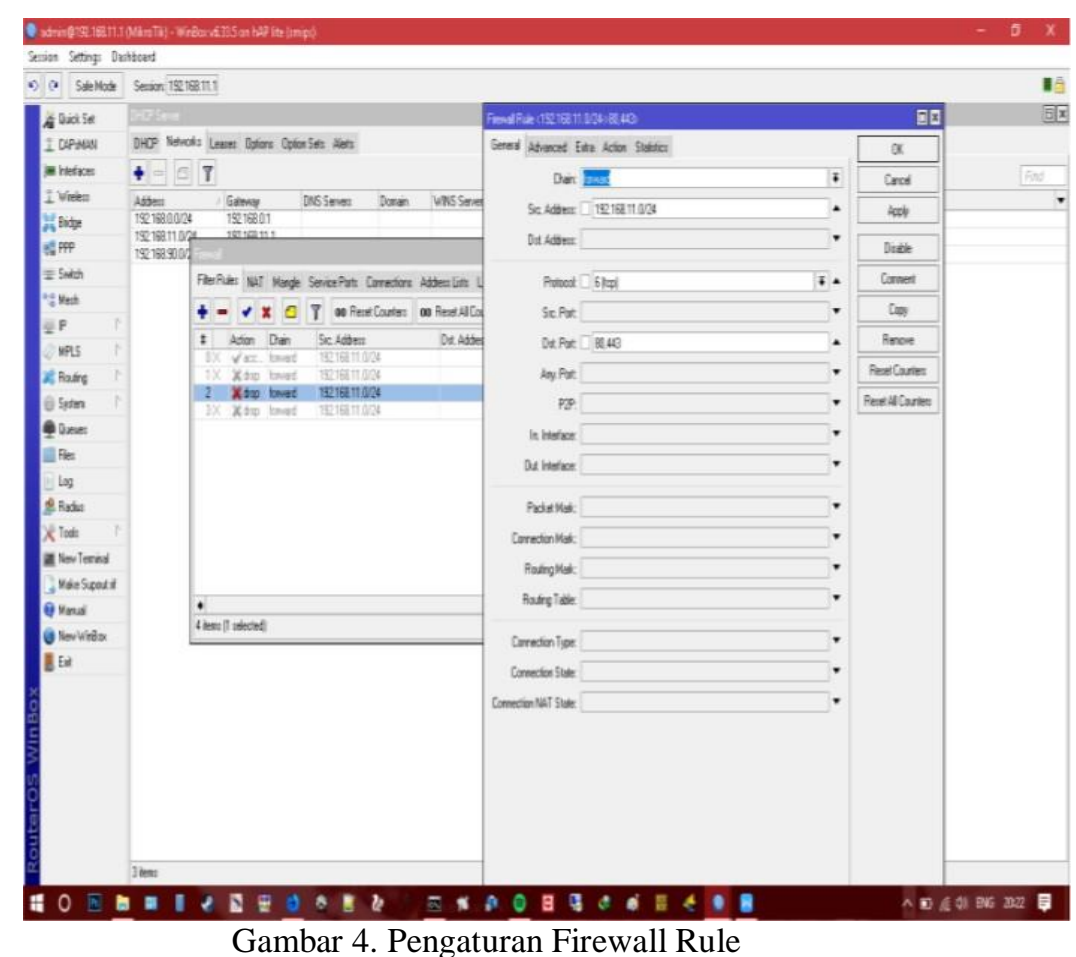

Dalam pengaturan firewall rule, pilih chain forward untuk menandai trafik yang akan menuju router. Dengan cara memilih "IN" dan "OUT" pada pengaturan firewall rule serta memasukkan src address 192.168.11.0/24. Hal ini berfungsi untuk mengubah source address dari paket data. Sehingga mikrotik akan membatasi semua komputer yang memiliki IP Address 192.168.11.0/24

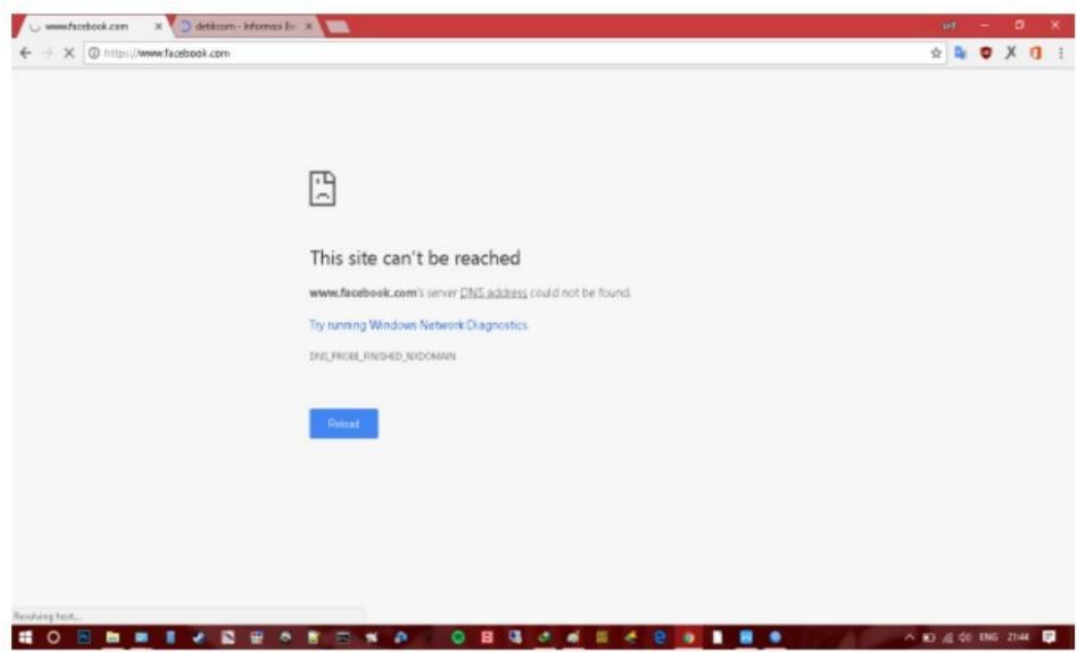

Gambar 5. Tampilan Blok Situs

Gambar tersebut menunjukkan bahwa situs www.facebook.com telah di blok. Saat ada client yang mengakses situs tersebut maka browser akan menampilkan seperti pada gambar 4.5 yang mengartikan "bahwa situs tidak dapat dijangkau"

SMA Negeri 4 Bandung memiliki fasilitas ruangan Kepala Sekolah, ruangan Wakil Kepala Sekolah, ruangan Tata Usaha, ruangan Kelas, ruangan Guru, dan ruangan Laboratorium Komputer. Ruangan-ruangan tersebut dapat saling berkumunikasi dengan menggunakan jaringan komputer. Namun jaringan komputer yang berada di SMA Negeri 4 Bandung memiliki proteksi yang minim. Proteksi yang dimiliki hanya sebatas antivirus, antivirus tersebut tidak dapat memproteksi dari situs-situs yang tidak diijinkan oleh pihak sekolah seperti situs facebook, 
instagram, dan youtube.

SMA Negeri 4 Bandung k memiliki skema jaringan komputer dengan komponen-komponen seperti: Modem, Router/Server, Switch, dan PC Client. Dimana komponen- komponen tersebut terhubung dalam jaringan yang luas dan mendunia yaitu internet. Kompnen tersebut memiliki IP address yang digunakan agar dapat saling terhubung dan berkomunikasi. IP address setiap komponen tersebut secara berurutan mulai dari 192.168.11.1 hingga 192.168.11.10. Dimana komponen tersebut dihubungan dengan jembatan (gateaway) dengan IP address 192.168.11.0.

IP address yang dimiliki setiap komponen jaringan tersebut diproteksi oleh mikrotik. Dalam hal ini, mikrotik akan mengamankan ruangan Kepala Sekolah, Wakil Kepala Sekolah, dan Tata Usaha. Mikrotik akan memblok atau membatasi beberapa situs yang diatur dan dikendalikan sesuai pihak sekolah. Sebagai contoh, bahwa situs yang di blok yaitu: facebook, instagram, dan youtube. Sehingga jika ruangan kepala sekolah, wakil kepala sekolah, dan tata usaha mencoba mengakses situs tersebut, maka mikrotik akan memblok situs tersebut dan menampilkan informasi bahwa "situs tersebut tidak dapat dijangkau".

Hal tersebut membuktikan bahwa SMA Negeri 4 Bandung telah memiliki proteksi jaringan komputer yang dapat diatur dan dikendalikan sesuai peraturan di SMA Negeri 4 Bandung. Berdasarkan wawancara dengan Kepala Sekolah, dengan adanya proteksi jaringan di SMA Negeri 4 Bandung dapat meningkatkan kinerja karyawan khususnya di SMA Negeri 4 Bandung.

\section{Kesimpulan}

Berdasarkan hasil wawancara dan observasi kepada pihak sekolah, maka dapat ditarik kesimpulan bahwa SMA Negeri 4 Bandung memiliki fasilitas ruangan Kepala Sekolah, Wakil Kepala Sekolah, Tata Usaha, Kelas, Guru, dan Laboratorium Komputer. Dimana ruangan ini saling terhubung dengan jaringan komputer. Ruangan Kepala Sekolah, Wakil Kepala Sekolah, dan Tata Usaha memiliki suatu keamanan jaringan dengan menggunakan antivirus. Antivirus yang digunakan tidak dapat membatasi/memblok suatu situs website. Sehingga karyawan SMA Negeri 4 Bandung dapat mengakases situs tersebut dan dapat menurunkan kinerja. Selanjutanya SMA Negeri 4 Bandung memiliki skema jaringan komputer dengan komponen-komponen salah satunya yaitu mikrotik. Mikrotik akan mengamankan ruangan Kepala Sekolah, Wakil Kepala Sekolah, dan Tata Usaha. Mikrotik akan memblok atau membatasi beberapa situs yang diatur dan dikendalikan sesuai pihak sekolah. Sebagai contoh, bahwa situs yang di blok yaitu: facebook, instagram, dan youtube. Sehingga jika ruangan kepala sekolah, wakil kepala sekolah, dan tata usaha mencoba mengakses situs tersebut, maka mikrotik akan memblok situs tersebut dan menampilkan informasi bahwa "situs tersebut tidak dapat dijangkau".

Berdasarkan hasil penelitian yang telah dilakukan, maka dapat diajukan saran yaitu: posisi server sebaiknya dipisahkan dengan laboratorium komputer. Karena suhu ruangan server rata-rata 20-250C, kelembaban ruangan sekitar 40\%-55\%, dan kebersihan ruangan menjadi salah satu faktor. Karena debu dapat menyebabkan pendingin menjadi tidak efektif dan membuat server cepat panas (overheating).

\section{Daftar Pustaka}

[1] Arikunto, S., 2006. Prosedur Penelitian Suatu Pendekatan Praktik. Jakarta: Rineka Cipta.

[2] Alexander Pandu Baskoro. (2011). "Analisis dan Perancangan Jaringan Komputer Studi Kasus: Inna Garuda Yogyakarta”. Tugs AkhirProram Studi Teknik Informatika Universitas Atma Jaya Yogyakarta.

[3] Basrowi \& Suwandi. 2008. Prosedur Penelitian Tindakan Kelas. Bogor: Ghalia Indonesia.

[4] Budi, R. (1999). “Keamanan Sistem Informasi Berbasis Internet”. PT. Insan Komunikasi Indonesia.

[5] Bandung.

[6] David, I. (1997). “An Analysis Of Security Incidents On The Internet 1989-1995” Enginering and Public Policy, Carnegia Mellon University. Tesis.

[7] Fadlil., A, Riadi, I, dan Aji, S. (2017). "Pengambangan Sistem Pengaman Jaringan KOmputer Berdasarkan Analisis Forensik Jaringan”. Jurnal Ilmu Teknik Elektro KOmputer dan Informatikan. Vol. 3. No. 1.

[8] Meylan Anggara, Yesi Novaria Kunang. (2013). "Analisis dan Arsitektur Desain Jaringan Komputer SMA Negeri 1 Muara Enim”. Tugas Akhir Jurusan Teknik Informatika Universitas Bina Darma, Palembang.

[9] Muhammad Nur Ikhsanto, Handoyo Widi Nugroho. (2015). “Analisa Performa dan Desain Jaringan Kompute Menggunakan Top - Down Network Desain Studi Kasus pada CV. Merah Putih". Jurnal TIM Darmajaya Vol.01 no 01. Mei 2015. ISSN: 2442 - 5567.

[10] Randy M, dkk. (2015). Perancangan dan Analisis Keamanan Jaringan Nirkabel Menggunakan Wireless Instruction Detection System. E-journal Teknik Elektro dan Komputer Vol.5. No.7. ISSN.2301-8402.

[11] Riyanto, Umi Fadlilah, Muhammad Kusban. (2013). “Analisis dan Perancangan Kemanan Jaringan Kabel dan Nirkabel pada Kantor Imigrasi Kelas II Kabupaten Karawang”. Tugas Akhir Program Studi Teknik Informatika Universitas Muhammadiyah Surakarta: Surakarta. 
[12] Singarimbun, Masir, dan Efendi S. 1989. Metode Penelitian Survei. Jakarta:

[13] T. Hidayat, Z. Zulfan, M. Munawir, and S. Susmanto, "Perbandingan Metode Antrian Paket HTB dan EDCA Untuk Layanan Multimedia Pada WLAN IEEE 802.11 n,” J. Nas. Komputasi dan Teknol. Inf., vol. 3, no. 2, pp. 132-143, 2020.

[14] A. A. Mamusung, N. B. Anshary, and R. A. Sumarni, "Perancangan Sistem Monitoring Gangguan Akses Wifi. Id PT Telkom Wilayah Jakarta Timur Berbasis Netbeans," J. Nas. Komputasi dan Teknol. Inf., vol. 3, no. 3, pp. 255-261, 2020. 